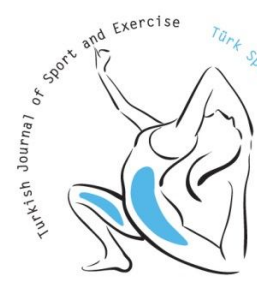

ISSN: 2147-5652

\title{
Anthropometric characteristics of Indian volleyball players in relation to their performance level
}

\author{
Vishaw GAURAV ${ }^{1}$, Amandeep SINGH²
}

${ }^{1}$ Department of Education, Government of Punjab, India.

2 Department of Physical Education, Guru Nanak Dev University, Amritsar, India.

Address correspondence to Amandeep Singh, prof_aman@yahoo.com

\begin{abstract}
The purpose of this study was to find out the differences in anthropometric characteristics of volleyball players in relation to their performance level (i.e., inter-university and inter-college). For this study, two hundred and forty ( $\mathrm{N}=240)$ male volleyball players (inter-university level, $\mathrm{N}_{1}=120$, inter-college level, $\mathrm{N}_{2}=120$ ) of age ranging from 18-25 years were selected as subjects from various colleges and universities of North India. The purposive sampling technique was used to select the subjects. All subjects were assessed for height, weight, lengths, circumference and diameters. The independent samples t-test revealed that inter-university volleyball players had significantly higher height $(p<0.05)$, weight $(p<0.05)$, leg length $(p<0.05)$, lower leg length $(p<0.05)$ than inter-college volleyball players. However, inter-college volleyball players had significantly greater forearm length $(p<0.05)$. The inter-university volleyball players also had significantly greater upper arm circumference $(p<0.05)$, forearm circumference $(p<0.05)$, thigh circumference $(p<0.05)$ and calf circumference $(p<0.05)$ than inter-college volleyball players. The inter-university volleyball players had significantly wider elbow diameter $(p<0.05)$, shoulder diameter $(p<0.05)$ and lesser hip diameter $(p<0.05)$ than inter-college volleyball players. It is concluded that there were significant differences between inter-university and inter-college volleyball players with regard to anthropometric characteristics. Inter-university players showed better anthropometric measurements as compared to inter-college volleyball player.
\end{abstract}

Keywords: Anthropometric characteristics, inter-university, inter-college, volleyball players.

\section{INTRODUCTION}

Anthropometric characteristics are related to a player's profile and might be used to predict a player's success. Anthropometric characteristics of players has been an interest of sports trainers, exercise scientists, physical education and sport medicine professionals for years and many of them assumed the practicing players might be expected to exhibited structural and functional characteristics that are specifically favorable for the sport (10). The knowledge of anthropometric characteristics is necessary to establish their importance for the success in competitive sport (17). Volleyball belongs to sport activities in which anthropometric characteristics of its participants influence the level of sport performance. It was established that volleyball players compared to most other athletes have distinctive anthrop-morphological characteristics $(4,9,16)$. In other words, successful participation in volleyball games, next to the high level of technical and tactical skills, also requires from each player's suitable anthropometric characteristics. Anthropometric characteristics are almost exclusively genetically determined therefore length and breadth measurements cannot be changed with training (11). Therefore, many previous studies have evaluated anthropometric profile of volleyball player $(1,2,3,6,7,8,12,15)$. Moreover, to our knowledge, there were no study has compared the anthropometric characteristics of Indian volleyball players at inter-university and inter-college performance level. Hence, the purpose of this study was to compare the anthropometric characteristics of volleyball players in relation to their performance level (i.e., inter-university and inter-college).

\section{MATERIAL \& METHODS}

\section{Participants}

For the present study, two hundred and forty $(\mathrm{N}=240)$ male volleyball players (inter-university level, $\mathrm{N}_{1}=120$, inter-college level, $\mathrm{N}_{2}=120$ ) of age ranging from 18-25 years were selected as subjects from various colleges and universities of North India. The purposive sampling technique was used to select the subjects. 


\section{Instruments}

The instruments used for collection of data were anthropometric rod, weighing machine, sliding caliper and steel tape.

\section{Variables}

Body weight was measured with portable weighing machine to the nearest $0.5 \mathrm{~kg}$. Height measurements were taken by using the standard anthropometric rod (HG-72, Nexgen ergonomics, Canada) to the nearest $0.5 \mathrm{~cm}$. Body mass index (BMI) was calculated by the following formulae: BMI $\left(\mathrm{Kg} / \mathrm{m}^{2}\right)=($ Body mass in $\mathrm{Kg}) /($ Stature in
Meters $)^{2}$. Widths and diameters of body parts were measured by using sliding caliper. Girths and lengths were taken with the steel tape to the nearest $0.5 \mathrm{~cm}$.

\section{Statistical Analysis}

Values are presented as mean values and SD. Independent samples $t$ test was used to test if population means estimated by two independent samples differed significantly. The level of significance was set at 0.05 . Data was analyzed using SPSS Version 16.0 (Statistical Package for the Social Sciences, version 16.0, SPSS Inc, Chicago, IL, USA)

Table 1. Variables and measurement units.

\begin{tabular}{llll}
\hline Variables & Measurement Unit & Variables & Measurement Unit \\
\hline & & & \\
Height & Centimeters & Upper arm circumference & Centimeters \\
Body Weight & Kilograms & Forearm circumference & Centimeters \\
Body Mass Index $(\mathrm{BMI})$ & $(\mathrm{kg} / \mathrm{m} 2)$ & Chest circumference & Centimeters \\
Arm Length & Centimeters & Thigh circumference & Centimeters \\
Upper Arm Length & Centimeters & Calf circumference & Centimeters \\
Forearm length & Centimeters & Elbow Diameter & Centimeters \\
Leg Length & Centimeters & Shoulder Diameter & Centimeters \\
Upper Leg Length & Centimeters & Hip Diameter & Centimeters \\
Lower Leg Length & Centimeters & Knee Diameter & \\
\end{tabular}

Table 2. Comparison of anthropometric characteristics between inter-university $(\mathrm{n}=120)$ and inter-college volleyball players ( $\mathrm{n}=120)$.

\begin{tabular}{|c|c|c|c|c|c|}
\hline \multirow{2}{*}{ Variables } & \multicolumn{2}{|c|}{ Inter-University Volleyball Players } & \multicolumn{2}{|c|}{ Inter-College Volleyball Players } & \multirow[t]{2}{*}{$\mathrm{t}$-Value } \\
\hline & Mean & SD & Mean & SD & \\
\hline Height $(\mathrm{cm})$ & 184.45 & 8.87 & 180.88 & 6.38 & $3.57^{*}$ \\
\hline Body Weight (kg) & 73.39 & 9.10 & 70.12 & 8.51 & $2.87^{*}$ \\
\hline $\mathrm{BMI}\left(\mathrm{kg} / \mathrm{m}^{2}\right)$ & 21.55 & 2.18 & 21.41 & 2.19 & 0.52 \\
\hline Arm Length (cm) & 81.40 & 4.04 & 81.34 & 4.23 & 0.12 \\
\hline Upper Arm Length (cm) & 33.69 & 2.25 & 33.50 & 2.13 & 0.64 \\
\hline Forearm length $(\mathrm{cm})$ & 29.01 & 1.44 & 29.89 & 2.55 & $3.26^{*}$ \\
\hline Leg Length $(\mathrm{cm})$ & 103.85 & 6.12 & 100.07 & 5.43 & $5.06^{*}$ \\
\hline Upper Leg Length(cm) & 50.91 & 4.26 & 50.50 & 5.21 & 0.66 \\
\hline Lower Leg Length (cm) & 44.37 & 2.82 & 42.99 & 3.08 & $3.61^{*}$ \\
\hline Upper arm circumference $(\mathrm{cm})$ & 26.55 & 2.04 & 24.92 & 2.45 & $5.57^{*}$ \\
\hline Forearm circumference $(\mathrm{cm})$ & 24.16 & 1.65 & 23.17 & 2.34 & $3.78^{*}$ \\
\hline Chest circumference $(\mathrm{cm})$ & 89.87 & 11.91 & 87.75 & 9.29 & 1.54 \\
\hline Thigh circumference $(\mathrm{cm})$ & 51.73 & 4.36 & 47.89 & 6.69 & $5.26^{*}$ \\
\hline Calf circumference $(\mathrm{cm})$ & 34.35 & 3.03 & 33.59 & 2.79 & $2.03^{*}$ \\
\hline Elbow Diameter (cm) & 8.09 & 0.59 & 7.74 & 0.80 & $3.90^{*}$ \\
\hline Shoulder Diameter (cm) & 43.51 & 2.22 & 42.47 & 2.12 & $3.68^{*}$ \\
\hline Hip Diameter (cm) & 29.05 & 4.57 & 30.62 & 2.13 & $3.41^{*}$ \\
\hline Knee Diameter (cm) & 9.96 & 0.59 & 9.82 & 0.91 & 1.34 \\
\hline
\end{tabular}




\section{RESULTS}

Descriptive statistics of various anthropometric characteristics of inter-university and inter-college volleyball players are given in Table 2 . Results of the present study revealed that inter-university volleyball players had significantly higher height $(p<0.05)$, weight $(p<0.05)$, leg length $(p<0.05)$, lower leg length $(\mathrm{p}<0.05)$ than inter-college volleyball players. However, inter-college volleyball players had significantly greater forearm length $(p<0.05)$. The inter-university volleyball players also had significantly greater upper arm circumference $(p<0.05)$, forearm circumference $(p<0.05)$, thigh circumference $(\mathrm{p}<0.05)$ and calf circumference $(p<0.05)$ than inter-college volleyball players. The inter-university volleyball players had significantly wider elbow diameter $(p<0.05)$, shoulder diameter $(p<0.05)$ and lesser hip diameter $(p<0.05)$ than intercollege volleyball players.

\section{DISCUSSION}

In the present study the anthropometric characteristics of the volleyball players have been evaluated in relation to their performance level (i.e., inter-university and inter-college). This study indicates the existence of differences between interuniversity and inter-college players. The overall results show that inter-university volleyball players were taller and heavier as compared to the intercollege volleyball players. Body height, being the most characteristic trait of volleyball players is significantly conditioned genetically (10). The mean height of the inter-university volleyball players $(184.45 \pm 8.87 \mathrm{~cm})$ in the present study is greater than the volleyball players of West Bengal, India $(173.10 \pm 4.19 \mathrm{~cm})$ reported by Bandyopadhya (1), but lesser than the English volleyball players (191.00 \pm 5.0 $\mathrm{cm}$ ) studied by Duncan et al. (3) and Brazilian national volleyball team $(197.0 \pm 8.0 \mathrm{~cm})$ studied by Petroski et al. (12). The taller player in volleyball has an advantage because they can easier control both, defensive and offensive actions over the top of the net. Thus, selection criteria can explain the observed results, as there has been a tendency to recruit the tallest players in this sport (9). Lower height of Indian volleyball players might be the one of the reason for their dismal performances at the international level. In volleyball, teams compete by manipulating skills of spiking and blocking high above the head. Therefore, the presence of tall players is an indispensable factor in the success of a volleyball team (7). The main purpose of volleyball players is achieving greater height on the net (14).
Higher body mass however, is a hurdle for volleyball players in achieving good jumping height (1). Maximum jump is one of the necessary components for spike and blocks during volleyball game. The mean body weight of inter-university volleyball players in present study is $(73.39 \pm 9.10 \mathrm{~kg})$ greater than the volleyball players of Guru Nanak Dev university, Amritsar, Indian $(73.02 \pm 7.58 \mathrm{~kg})$ reported by Gaurav et al. (7), but lesser than the Brazilian national volleyball team $(90.3 \pm 13.0 \mathrm{~kg})$ studied by Petroski et al. (12). In the present study, significantly greater body weight of inter-university volleyball players than inter-college volleyball players might be disadvantageous for interuniversity volleyball players in attaining a good jumping height as they have to lift a greater weight. In comparison to previous studies on volleyball players of other countries, $(4,9,12)$ the interuniversity volleyball players in present study have lower height and body weight. In this study the inter-college volleyball players had significantly greater forearm length than inter-university volleyball players because anthropometric characteristics are almost exclusively genetically determined therefore length and breadth measurements cannot be changed with training (11). On the other hand inter-university volleyball players had significantly greater upper arm and forearm circumference. Results indicated that the interuniversity volleyball players had significantly greater thigh and calf circumference than the intercollege volleyball players. Fattahi et al. (5) observed that greater thigh and calf circumference has significant correlation with jump in volleyball players. Muscle size effects force producing and jump performance. The inter-university volleyball players also possess higher diameters (i.e., elbow diameter and shoulder diameter) which show better growth and development as compared to intercollege volleyball players. The inter-university volleyball players had significantly lesser hip diameter than the inter-college volleyball players. These differences might be due to regular training program of inter-university volleyball players. Considering that in most of the variables there were significant differences between inter-university and inter-college volleyball players and the interuniversity players showed better anthropometric measurements, it is concluded that various anthropometric characteristics has clear impact on the performance of the volleyball players. This study indicate the need for further research regarding playing position-by-playing position analysis of anthropometric characteristics of 
volleyball players including correlations with players' physical performance.

\section{ACKNOWLEDGEMENTS}

Sincere thanks to Coaches who extended their enthusiastic co-operation in collecting the necessary data and to all those volleyball players without whom this research was not possible. We acknowledge the immense help received from the scholars whose articles are cited and included in references of this paper. We are also grateful to authors/editors/publishers of all those articles, journals and books from where the literature for this paper has been reviewed and discussed.

\section{REFERENCES}

1. Bandyopadhya A. Anthropometry and body composition in soccer and volleyball players in West Bengal, India. J Physiological Anthropology, 2007; 26(4): 501-505.

2. Bayios IA, Bergeles NK, Apostolidis NG, Noutsos KS, Koskolou MD. Anthropometric, body composition and somatotype differences of Greek elite female basketball, volleyball and handball players. Journal of Sports Medicine and Physical Fitness, 2006; 46(2): 271-280.

3. Duncan MJ, Woodfield L, Al-Nakeeb Y. Anthropometric and physiological characteristics of junior elite volleyball players. Br J Sports Med, 2006; 40(7): 640-651.

4. Ercolessi D. La caduta dal salto. Super Volley, 1999; 1: 79-82.

5. Fattahi A, Ameli M, Sadeghi H, Mahmoodi B. Relationship between anthropometric parameters with vertical jump in male elite volleyball players due to game's position. J Hum Sport Exerc, 2012; 7(3): 714-726.

6. Gabbett T, Georgieff B. Physiological and anthropometric characteristics of Australian junior national, state, and novice volleyball players. J Strength Cond Res, 2007; 21: 902-908.
7. Gaurav V, Singh M, Singh S. Anthropometric characteristics, somatotyping and body composition of volleyball and basketball players. Journal of Physical Education and Sports Management, 2010; 1(3): 28-32.

8. Hadzic R, Belica D, Popovic S. Comparative study of anthropometric measurement and body composition between elite basketball and volleyball players. PESH, 2012; 1: 103-108.

9. Jankovic V, Marelic N. Odbojka (Volleyball). Fakultet za fizičku kulturu (Faculty of Physical Education Zagreb), 1995, 7-9.

10. Milicerowa H. Somatic traits as a main criterion in the process of sport selection. AWF Warszawa. 1973, 5, 51-109. (In Polish).differ in somatic characteristics from the general population.

11. Norton K, Olds T. Morphological evolution of athletes over the 20th century. Sports Medicine, 2001; 31: 763-783.

12. Petroski EL, Fraro JD, Fidelix YL, Silva DAS, Pires-neto CS, Dourado AC, Rocha MA, Stanganelli LCR, Oncken P, Viera FS. Anthropometric, morphological and somatotype characteristics of athletes of the Brazilian Men's volleyball team: an 11-year descriptive study. Rev Bras Cineantropom Desempenho Hum, 2013; 15(2): 184-192.

13. Singh S, Singh K, Singh M. Anthropometric measurements, body composition and somatotyping of high jumpers. Brazilian Journal of Biomotricity, 2010; 4(4): 266-271.

14. Stec M, Smulsky V. The estimation criteria of jump actions of high performance female volleyball players. Research Yearbook, 2007; 13: 77-8.

15. Toriala AL, Adeniran S, Ogunremi RT. Body composition and anthropometric characteristics of elite male basketball and volleyball players. J Sports Med, 1987; 27: 235-239.

16. Ugarkovic D. Biomedicinske osnove sportske medicine (Biomedical foundations of sports medicine). Novi Sad, 2004.

17. Viswanathan J, Chandrasekaran K. Optimizing position-wise anthropometric models for prediction of playing ability among elite Indian basketball players. International Journal of Sports Science and Engineering, 2011; 5(2): 67-76. 